\title{
Dietary assessment in the elderly: application of a two-step semi- quantitative food frequency questionnaire for epidemiological studies
}

\author{
K. Klipstein-Grobusch,*† J. C. M. Witteman,* \\ J. H. den Breeijen, $\neq$ R. A. Goldbohm, $\neq$ A. Hofman,* \\ P. T. V. M. de Jong, *§II H. A. Pols** and D. E. Grobbee* \\ *Department of Epidemiology \& Biostatistics, and **Department of Internal \\ Medicine, Erasmus University Medical School, Rotterdam, The Netherlands; \\ +Department of Epidemiology, German Institute of Human Nutrition, Potsdam- \\ Rehbrücke, Germany; ¥TNO Nutrition and Food Research Institute, Zeist, \\ The Netherlands; §The Netherlands Ophthalmolic Research Insitute, Amsterdam, \\ The Netherlands; IIDepartment of Ophthalmology, Academic Medical Center, \\ Amsterdam, The Netherlands
}

Objective: Description and application of an adapted semiquantitative food frequency questionnaire (SFFQ) for dietary assessment in the elderly population of the Rotterdam Study.

Design: Dietary assessment consisting of a two-step approach was performed in 5434 participants (2225 men, 3029 women) of the Rotterdam Study from 1990 to 1993, a population-based prospective cohort of 7983 subjects aged 55-95 years (participation rate $78 \%$ ).

Statistical analysis: Nutrient intake was calculated for men and women in four age groups (55-64 years, 65-74 years, 75-84 years, 85-95 years) and linear trend analysis for differences in mean nutrient intake across age groups (55-64 years, 65-74 years, 75-95 years) by regression analysis was conducted. The influence of baseline characteristics on energy and nutrient intakes adjusted by age and sex was investigated by one-way-analysis of variance.

Results: The adapted SFFQ made it possible to measure nutrient intake in the elderly within a limited time frame $(2 \times 20 \mathrm{~min})$ across a wide age range (55-95 years). For nutrient intake we observed a general decline in mean intake of energy and most nutrients with age in men. In women the relation with age was not consistent: for most nutrients mean intake showed a decrease with age (e.g. water, magnesium, potassium), for some an increase (e.g. total fat, saturated fat, mono/disaccharides), and some nutrients showed no substantial change (e.g. calcium, retinol). Reported nutrient intake was influenced by body mass index, smoking status, socioeconomic status and activities of daily living. A prescribed diet was reported by $12.9 \%$ of participants and $34.6 \%$ used supplements on a regular basis.

Conclusions: The described two-step approach for dietary assessment in the elderly facilitated collection of data on dietary habits across a wide age range and within a limited time frame making it a suitable instrument for application in large-scale epidemiological studies in the elderly.

Key words: dietary assessment, elderly, food frequency questionnaire, nutrient intake 


\section{Introduction}

Diet is an important aspect of lifestyle and may affect life expectancy, morbidity and mortality of older adults. Data on the nutrient intake and the nutritional status of the elderly in largescale studies are scarce, especially for those older than 75 years of age. Thus far, application of appropriate methods for dietary assessment in epidemiological studies has been difficult in elderly populations. Limited recall due to fading memory or disabilities in sight or attention may require a more complicated dietary assessment and may result in a higher respondent burden (Kelsey et al., 1989; Van Staveren et al., 1994) and low participation rate. To simplify dietary assessment without loss of validity and precision, a semiquantitative food frequency questionnaire was adapted for use in an elderly population. In this paper the method of dietary assessment will be introduced and nutrient intake in participants of the Rotterdam Study will be described.

\section{Methods}

\section{Study design and subjects}

The Rotterdam Study is a community-based prospective cohort study among 7983 subjects aged 55 years and over, living in Ommoord, an urban district in Rotterdam, the Netherlands. The rationale and design of the Rotterdam Study have been described previously (Hofman et al., 1991). In short, the Rotterdam Study is a large-scale prospective cohort study on prevalence, incidence and determinants of cardiovascular, neurological, locomotor and ophthalmological diseases. The study comprised an extensive general home interview (participation rate $78 \%$ ) and two visits at a research centre for a clinical examination (participation rate 69\%). The study has been approved by the Medical Ethics

Correspondence: Dr J. C. M Witteman, Department of Epidemiology \& Biostatistics, Erasmus University, Medical School, PO Box 1738, 3000 DR Rotterdam, The Netherlands. Tel: +31 1040873 65; fax:+31 10 4365933; e-mail: Witteman@epib.fgg.eur.nl
Committee of Erasmus University, Rotterdam, and written consent was obtained from participants. Dietary assessment was undertaken to investigate the role of nutrition and nutrition-related factors in the development of chronic diseases. Dietary assessment was performed during the second visit of the participants $(n=7006)$ at the research centre by dietitians. It was not performed in participants of the pilot study $(n=277)$, in those living in nursing homes $(n=479)$ and in persons with known reduced cognitive function assessed by a neuropsychological test prior to dietary assessment $(n=122)$. Owing to logistic reasons (e.g. unavailability of a dietitian) no dietary assessment could be carried out in an additional 482 persons. A dietary interview was thus obtained in 5646 persons; 212 subjects were excluded from analysis because dietitians considered their reported dietary intake unreliable, i.e. because participants answers during the dietary interview were either too inconsistent or too incomplete. This resulted in 5434 participants, 2225 men (41\%) and 3209 women (59\%), aged 55-95 years, for the present dietary analysis.

\section{Dietary assessment by semiquantitative food} frequency questionnaire (SFFQ)

The instrument to assess nutrient intake in the Rotterdam Study is a modification of a selfadministered mailed semiquantitative food frequency questionnaire (SFFQ) used in a large-scale prospective cohort study on diet and cancer in the Netherlands (NLCS) (Van den Brandt et al., 1990). Data on the validity and reproducibility of the original questionnaire with 150 food items have been reported (Goldbohm et al., 1994, 1995). Modification consisted mainly of a different mode of administration, collection of more detailed information on vegetable, fruit, and meat consumption, and inclusion of some additional items. The modified SFFQ contained 170 food items in 13 food groups and general questions about dietary habits (e.g. type of coffee, use of milk/sugar in coffee, change in food habits) to assess habitual food intake during the past year.

The dietary assessment was undertaken in two consecutive phases as outlined in Table 1. First, participants were asked to report foods 
Table 1. Dietary assessment in the Rotterdam Study

\begin{tabular}{|c|c|c|}
\hline & $\begin{array}{l}\text { Phase 1: } \\
\text { Self-administered questionnaire }\end{array}$ & $\begin{array}{l}\text { Phase 2: } \\
\text { Dietary interview }\end{array}$ \\
\hline Place of application & at home & at the study centre \\
\hline Method of dietary assessment & meal-based checklist of foods & structured interview \\
\hline Mode of application & self-administered & by dietitian \\
\hline \multirow[t]{2}{*}{ Type of information collected } & $\begin{array}{l}\text { foods consumed at least twice a } \\
\text { month over the past year }\end{array}$ & $\begin{array}{l}\text { Quantification (amount, } \\
\text { frequency) of reported food } \\
\text { items based on the self- } \\
\text { administered questionnaire over } \\
\text { the past year }\end{array}$ \\
\hline & $\begin{array}{l}\text { in addition questions on } \\
\text { - dietary fats/oils (type) } \\
\text { - vegetables/fruits (season; } \\
\text { preparation) } \\
\text { - additional foods consumed } \\
\text { regularly and not listed in } \\
\text { the questionnaire }\end{array}$ & $\begin{array}{l}\text { in addition questions on } \\
\text { - reliability } \\
\text { - dietary habits } \\
\text { - prescribed diets } \\
\text { - supplements }\end{array}$ \\
\hline Time for completion & 20 min (average) & $20 \min$ (allocated) \\
\hline
\end{tabular}

consumed regularly (at least twice a month) by use of a self-administered questionnaire consisting mainly of a meal-based checklist of foods. The questionnaire was explained to each participant during a home visit by a trained research assistant. It was filled in at home and collected at the research centre. Participants had to mark the foods they had consumed at least twice a month in the preceeding year. Questions on fruit and vegetables were asked with respect to season (summer and winter) and preparation (raw, cooked). In addition, type and brand of dietary fats and oils used on bread, for cooking or as salad dressing were asked. Finally, subjects were asked whether additional foods not included in the questionnaire were consumed on a regular basis (frequency and amount specified). Average time for completion of the questionnaire was $20 \mathrm{~min}$. The availability of the completed checklist of foods allowed for a more time-efficient dietary interview at the research centre. The dietary interview was conducted by dietitians trained in the use of this method. The dietitians aimed at obtaining accurate information on amount and consumption frequency of food items noted by participants as consumed frequently. For each item the frequency was recorded in times per day, week or month. The number of servings per frequency was expressed in natural units (e.g. slice of bread, apple), household measures (e.g. cup, spoon) or grams (cooked vegetables, mixed dishes). General questions to check the consistency of the completed dietary questionnaire were asked such as total number of warm meals per week. Additional information about dietary habits and supplement use (e.g. type, amount and frequency) during the past year was obtained, as well as comprehensive data on prescribed diets that were currently followed. The time allocated to the dietary interview was $20 \mathrm{~min}$; the time needed to complete both parts of the dietary assessment was thus approximately $40 \mathrm{~min}$.

All data were entered into an interactive computer program. Average time for data entry was $20 \mathrm{~min}$. For calculation of frequency and amounts of foods consumed a computer application was developed. Questionnaires were checked for completeness by an interactive data-entry program and automatically coded for later conversion into nutrients. The program checked further for internal consistency, range and other response errors. The conversion from foods to energy and 
nutrient intakes was established with a computerized version of the Dutch Food Composition Table (Food and Nutriton Council, 1993). Intake through dietetic products and nutritional supplements was not taken into account since brand labels were not recorded with sufficient accuracy.

Validity of the modified SFFQ was assessed in a subsample of 80 men and women aged 55-75 years of the Rotterdam Study as previously described (Klipstein-Grobusch et al., 1998). Multiple food records (FR) collected over a 1-year period served as a reference. Twenty-four-hour urine urea was used as an indirect marker for protein intake. Compared with FR, the SFFQ generally overestimated nutrient intake as reflected by difference in means and the ratio of SFFQ to FR. Energy adjustment reduced the observed overestimation. Validation of protein intake from SFFQ with estimated protein excretion from 24-h urea indicated overestimation of protein intake by SFFQ. The ability of the SFFQ to rank subjects adequately according to their dietary intake was reflected by Pearsons correlation coefficients varying from 0.44 to 0.85 adjusted for age, sex, total energy intake (Willett \& Stampfer, 1986) and within-person variability in daily intake (Beaton et al., 1983) and by correct classification into the same or adjacent quintile $(75.8 \%$ of crude and $76.8 \%$ for energy-adjusted data).

\section{Data analysis}

Nutrient intake was calculated for men and women in four age groups (55-64 years, 65-74 years, 75-84 years, 85-95 years). Linear trend analysis for differences in mean nutrient intake across these age groups was carried out by regression analysis. Influence of baseline characteristics such as smoking status, body mass index (BMI), disability and reported difficulty with food intake on energy and nutrient intakes adjusted by age and sex was investigated by one-way-analysis of variance. When testing for statistical significance, natural logarithm (energy, protein, vegetable protein, fat, satured fat, monounsaturated fat, carbohydrates, mono/disaccharides, fibre, water, calcium, phosphorus, potassium, iron, zinc, retinol, $\mathrm{B}$ vitamins, vitamin $\mathrm{E}$ and $\beta$ carotene), respectively, square root transformation (polyunsaturated fat, linoleic acid, polysaccharides, cholesterol, sodium, magnesium and vitamin C) was used for skewed nutrients to improve their distribution towards normality. Associations are expressed as odds ratios with $95 \%$ confidence interval (CI). Results were considered statistically different at the two-sided 0.05 alpha level. Statistical analyses was performed using SAS-26 statistical software package version 6.11 (SAS Institute, Cary, NC, USA).

For evaluation of plausibility of dietary intake data, the ratio of energy intake (EI) to basal metabolic rate (BMR) was calculated. EI/ BMR is regarded as a satisfactory independent validator of energy intake (Black et al., 1991; Garrow, 1995). BMR was predicted from standard equations based on age-specific formulae according to the Department of Health (1994).

\section{Results}

\section{Descriptive characteristics}

Table 2 summarizes selected characteristics of the study group. Mean age was 67 years (range 55-93) for men and 68 years (range 55-94) for women. Significant trends towards lower measured body weight and lower measured height at older age were observed. These changes with age were more pronounced in men. Body mass index (BMI) decreased with age in men whereas in women it increased slightly. Calculated basal metabolic rate averaged 6.9 MJ day ${ }^{-1}$ (SD 0.7) for men and $5.6 \mathrm{MJ} \mathrm{day}^{-1}$ (SD 0.5) for women and declined significantly with age. Mean ratio of energy intake to basal metabolic rate (EI/BMR) was 1.38 (SD 0.32) for men and 1.34 (SD 0.33) for women, and was significantly related to age.

Indicators of activities of daily living as well as the percentage of those living independently decreased steadily with age. More women were living in a single household than men. Percentage with a low monthly equivalent household income $(<1500 \mathrm{Hfl}(680 €))$ was higher for women $(26.4 \%)$ than for men $(12.6 \%)$. Education level was generally lower for women and decreased with age. A 


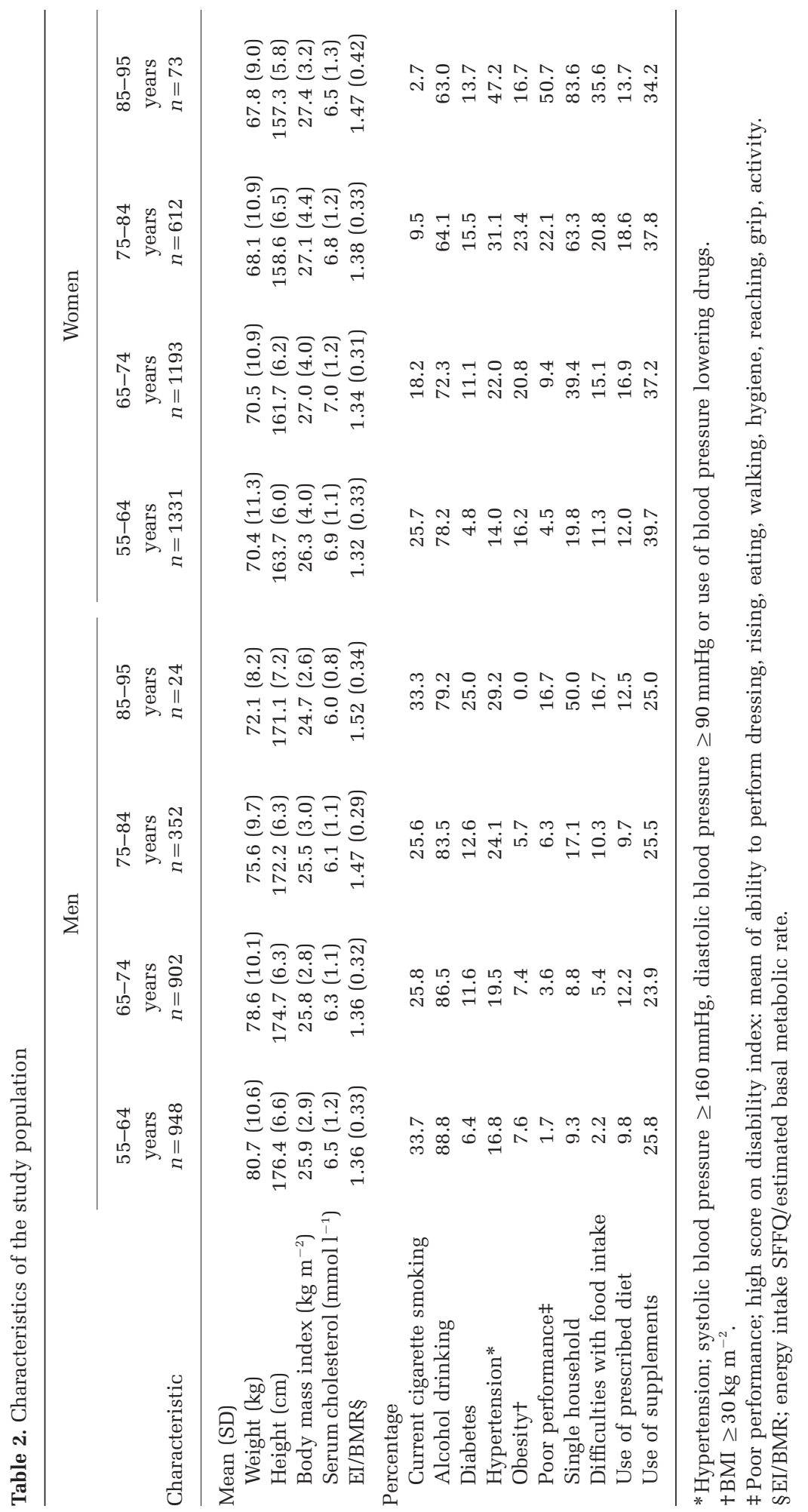

(C) 1999 Blackwell Science Ltd, J Hum Nutr Dietet 12, 361-373 
completed primary education as highest degree obtained was reported by $24.0 \%$ of men and $42.1 \%$ of women, whereas $14.7 \%$ of men and $4.3 \%$ of women reported a college or university education. Comparison of baseline characteristics as given in Table 2 for the study population undergoing dietary assessment with the total study population revealed no differences for the majority of characteristics. The prevalence of obesity was somewhat lower for women in the total study population, whereas the percentage of those with poor physical performance (activities of daily living), living alone, difficulties with food intake and a low income was higher in the total population. Stratification by age revealed that these differences were mainly due to abberant values in the oldest age group (85-95 years).

\section{Energy and nutrient intake}

Men reported significantly higher mean intakes of energy and all nutrients from food intake compared with women, except for water and calcium, which were similar, and vitamin $\mathrm{C}$, which was lower in men. Mean alcohol consumption among drinkers of any alcohol (men $87 \%$, women $73 \%$ ) was higher in men than in women with $18.9 \mathrm{~g}$ day $^{-1}$ compared with $8.3 \mathrm{~g} \mathrm{day}^{-1}$. Linear trend analysis across age groups showed a general decline in energy and nutrient intake with advancing age in men which was significant for most nutrients (Tables 3 and 4). However, percentage of energy from saturated fat, mono/disaccharides and carbohydrates increased whereas percentage of energy from protein decreased. In women, mean intake of most nutrients declined (e.g. water, protein, magnesium, potassium, zinc, pyridoxine, $\beta$-carotene), but some increased (e.g. total fat, saturated fat, mono/ disaccharides, respectively, the percentage of energy of these nutrients), and some showed no substantial changes (e.g. calcium, retinol) (Tables 5 and 6).

Some baseline characteristics (age- and sexadjusted) were related to energy and nutrient intake. A significant inverse relationship between BMI and reported energy intake was present for both men and women and this was consistent over age groups. Current cigarette smokers had significantly higher intakes of macronutrients (e.g. carbohydrates, mono/ disaccharides, saturated fat) and significantly lower intakes of micronutrients (e.g. calcium, vitamin C) compared with never and former smokers. Lower educational attainment was associated with a generally higher intake of macronutrients and a less favourable fat composition (van Rossum, unpublished observations). Disability and reported difficulty with food intake were associated with lower intakes of energy and most nutrients. Living independently compared with living in a service flat only marginally influenced energy and nutrient intakes.

\section{Dietary regimen}

A prescribed diet was reported by 231 men $(10.4 \%)$ and 469 women $(15.3 \%)$. Figure 1 shows the percentage of men and women currently following different types of diet. Only for women was there a significant increase with age in the percentage of prescribed diets (ANOvA; $P<0.0001$ ) (Table 2). Of the 700 men and women reporting a prescribed diet, 153 followed a combined dietary regime. The most commonly used combinations were a sodium/fat-restricted diet, a fat/cholesterol-restricted diet, or a diabetes diet with sodium or fat restriction. Subjects currently following a prescribed diet generally reported lower energy and nutrient intakes than subjects not on a dietary regimen. The observed decrease in energy and nutrient intake was more pronounced for macronutrients than for micronutrients with the exception of sodium. The reported energy and nutrient intake between different dietary regimes differed according to the aim of the prescribed diet.

\section{Supplementation}

Information on supplement use during the past year was obtained in 5334 persons (2183 men; 3151 women). Of those, 1267 women $(40.2 \%)$ and 580 men $(26.6 \%)$ reported regular use of supplements. Consumption of more than two different supplements was reported by $4.8 \%$ of men and $9.3 \%$ of women. The type of supplements consumed included vitamins, minerals and a variety of preparations such as garlic, brewers yeast, ginseng and fishoil. Use 
Table 3. Mean (SD) daily intake of energy and selected nutrients, energy distribution and nutrient density for selected nutrients of men in the Rotterdam Study

\begin{tabular}{|c|c|c|c|c|c|}
\hline & $\begin{array}{c}55-64 \text { years } \\
n=948\end{array}$ & $\begin{array}{c}65-74 \text { years } \\
n=902\end{array}$ & $\begin{array}{c}75-84 \text { years } \\
n=352\end{array}$ & $\begin{array}{c}85-95 \text { years } \\
n=24\end{array}$ & $\begin{array}{l}\text { Test for } \\
\text { trendt }\end{array}$ \\
\hline \multicolumn{6}{|l|}{ Nutrient } \\
\hline Energy (MJ) & $9.7(2.3)$ & $9.3(2.1)$ & $8.9(1.7)$ & $9.1(1.9)$ & $* * *$ \\
\hline \multicolumn{6}{|l|}{ Protein } \\
\hline total (g) & $93.3(22.1)$ & $86.2(18.4)$ & $82.0(19.1)$ & $82.4(17.4)$ & $* * *$ \\
\hline vegetable protein (g) & $32.6(9.3)$ & $30.8(8.4)$ & $29.2(7.2)$ & $30.2(7.0)$ & $* * *$ \\
\hline \multicolumn{6}{|l|}{ Fat } \\
\hline total (g) & $94.6(29.8)$ & $90.9(28.4)$ & $87.6(24.3)$ & $90.6(27.5)$ & $* * *$ \\
\hline saturated fat (g) & $36.8(13.0)$ & $35.4(12.4)$ & $34.7(10.6)$ & $36.8(12.2)$ & $*$ \\
\hline monounsaturated fat (g) & $32.6(11.7)$ & $31.0(10.8)$ & $29.6(9.7)$ & $31.3(13.2)$ & $* * *$ \\
\hline polyunsaturated fat (g) & $18.3(8.3)$ & $17.9(8.5)$ & $16.9(7.9)$ & $16.2(8.2)$ & $* *$ \\
\hline linoleic acid (g) & $15.2(8.1)$ & $14.8(8.2)$ & $13.9(7.8)$ & $13.4(8.1)$ & ** \\
\hline \multicolumn{6}{|l|}{ Carbohydrates } \\
\hline total (g) & $243.3(70.8)$ & $233.1(64.4)$ & $228.8(53 . \&)$ & $229.5(54.8)$ & ** \\
\hline mono/disaccharides (g) & $118.1(50.4)$ & $114.7(46.1)$ & $115.9(39.8)$ & $112.1(43.6)$ & ns \\
\hline polysaccharides (g) & $124.1(35.3)$ & $117.5(30.9)$ & $112.0(26.8)$ & $115.9(30.4)$ & $* * *$ \\
\hline Cholesterol (mg) & $268(94)$ & $254(85)$ & $247(83)$ & $254(94)$ & $* * *$ \\
\hline Dietary fibre (g) & $18.6(5.6)$ & $17.6(5.3)$ & $16.9(4.3)$ & $16.7(4.4)$ & $* * *$ \\
\hline Water (ml) & $2543(655)$ & 2344 (538) & $2279(504)$ & $2166(441)$ & $* * *$ \\
\hline Alcohol (g)‡ & $19.9(19.7)$ & $18.8(19.2)$ & $16.0(16.3)$ & $18.5(13.7)$ & * \\
\hline \multicolumn{6}{|l|}{ Energy density } \\
\hline Cholesterol $\left(\mathrm{mg} \mathrm{MJ}^{-1}\right)$ & $27.7(7.2)$ & $27.5(7.0)$ & $27.8(7.8)$ & $28.2(7.0)$ & $\mathrm{ns}$ \\
\hline Dietary fibre $\left(\mathrm{g} \mathrm{MJ}^{-1}\right)$ & $2.0(0.5)$ & $1.9(0.5)$ & $1.9(0.5)$ & $1.9(0.5)$ & ns \\
\hline \multicolumn{6}{|l|}{ Energy distribution } \\
\hline \multicolumn{6}{|l|}{ Energy from: } \\
\hline protein \% & $16.3(2.8)$ & $15.8(2.8)$ & $15.5(2.8)$ & $15.5(2.9)$ & $* * *$ \\
\hline fat $\%$ & $36.3(6.0)$ & $36.7(6.0)$ & $36.8(6.3)$ & $37.3(5.8)$ & ns \\
\hline saturated fat \% & $14.1(3.0)$ & $14.3(3.0)$ & $14.6(3.2)$ & $15.1(3.1)$ & * \\
\hline carbohydrates \% & $41.9(6.9)$ & $42.2(7.1)$ & $43.2(7.1)$ & $42.6(7.2)$ & $* *$ \\
\hline mono/disaccharides \% & $20.2(6.3)$ & $20.6(6.2)$ & $21.8(6.3)$ & $20.5(6.0)$ & $* * *$ \\
\hline
\end{tabular}

†Test for trend across age groups (55-64 years, 65-74 years, 74-95 years).

ns $=$ not significant.

$* P<0.05$.

$* * P<0.001$.

$* * * P<0.0001$.

¥Mean alcohol consumption of men drinking alcohol (87\%).

of supplementation showed no clear trend with age (Table 2). The most popular supplement was garlic $(n=572)$, followed by tonicum supplement $(n=107)$ and brewers yeast $(n=86)$. Use of vitamin/mineral supplementation was reported by 307 men $(14.1 \%)$ and 793 women $(25.2 \%)$. The most frequently comsumed mineral/vitamin supplements were multivitamins $(n=329)$, vitamin C $(n=309)$, calcium $(n=229)$, vitamin B preparation $(n=135)$, multiminerals $(n=123)$ and vitamin $\mathrm{D}(n=83)$.

\section{Discussion}

In this paper we have described a new approach to improve the feasability of dietary assessment by SFFQ in the elderly. The assessment comprised a simple selfadminstered dietary questionnaire which formed the basis for an interview with a trained dietitian. Average time for completion of the self-administered questionnaire was $20 \mathrm{~min}$ and a further 20 min were allocated to conduct the dietary interview. Information concerning 
Table 4. Mean (SD) daily intake of selected vitamins and minerals of men in the Rotterdam Study

\begin{tabular}{lccccc}
\hline & $\begin{array}{c}55-64 \text { years } \\
n=948\end{array}$ & $\begin{array}{c}65-74 \text { years } \\
n=902\end{array}$ & $\begin{array}{c}75-84 \text { years } \\
n=352\end{array}$ & $\begin{array}{c}85-95 \text { years } \\
n=24\end{array}$ & $\begin{array}{c}\text { Test for } \\
\text { trendt }\end{array}$ \\
\hline Minerals & & & & & \\
$\quad$ Calcium (mg) & $1205(471)$ & $1117(414)$ & $1081(386)$ & $1035(297)$ & $* * *$ \\
Phosphor (mg) & $1843(820)$ & $1673(802)$ & $1604(646)$ & $1514(432)$ & $* * *$ \\
Iron (mg) & $13.8(3.2)$ & $12.8(2.9)$ & $12.3(2.8)$ & $11.8(2.5)$ & $* * *$ \\
Sodium (mg)§ & $2584(761)$ & $2385(681)$ & $2317(628)$ & $2408(893)$ & $* * *$ \\
Potassium (mg) & $4083(910)$ & $3823(817)$ & $3653(739)$ & $3630(743)$ & $* * *$ \\
Magnesium (mg) & $350.9(86.3)$ & $320.0(74.5)$ & $306.9(68.1)$ & $307.4(68.4)$ & $* * *$ \\
Zinc (mg) & $12.1(3.0)$ & $11.2(2.5)$ & $10.7(2.6)$ & $10.2(2.3)$ & $* * *$ \\
Vitamins & & & & & \\
Vitamin A (mg RE) & $0.93(0.47)$ & $0.87(0.38)$ & $0.88(0.36)$ & $0.78(0.23)$ & $*$ \\
$\quad \beta$-carotene (mg) & $1.66(0.70)$ & $1.49(0.59)$ & $1.42(0.56)$ & $1.19(0.47)$ & $* * *$ \\
Thiamin (mg) & $1.27(0.34)$ & $1.17(0.31)$ & $1.13(0.36)$ & $1.09(0.24)$ & $* * *$ \\
Riboflavin (mg) & $1.72(0.62)$ & $1.58(0.53)$ & $1.57(0.50)$ & $1.57(0.42)$ & $* * *$ \\
Pyridoxine (mg) & $1.84(0.45)$ & $1.71(0.40)$ & $1.63(0.38)$ & $1.63(0.34)$ & $* * *$ \\
$\quad$ Niacin (mg) & $12.9(4.7)$ & $11.0(3.8)$ & $9.9(3.0)$ & $10.1(3.1)$ & $* * *$ \\
Tocopherol (mg eqv) & $15.6(6.6)$ & $15.3(6.9)$ & $14.7(6.3)$ & $13.3(6.8)$ & $* *$ \\
Vitamin C (g) & $116.6(52.4)$ & $114.8(49.5)$ & $112.8(46.7)$ & $92.5(33.5)$ & $n$ \\
\hline
\end{tabular}

†Test for trend across age groups (55-64 years, 65-74 years, 74-95 years).

$\mathrm{ns}=$ not significant.

$* P<0.05$.

$* * P<0.001$.

$* * * P<0.0001$.

$\S$ Sodium intake from food only.

dietary intake was obtained in 5434 participants of the Rotterdam Study and intake of a variety of nutrients was calculated. In men, a general decline in intake of energy and most nutrients was observed with age. In women, the relation with age was not consistent: mean intake for most nutrients showed a significant decline; some showed an increase, and colleagues showed no substantial change with age. Body mass index, smoking status, socioeconomic status and activities of daily living were observed to influence reported nutrient intake.

Before interpreting the results, some methodological aspects of the study need to be discussed. The Rotterdam Study is a community-based prospective cohort study in Rotterdam. Baseline data were collected by means of an extensive general home interview and two visits at the research centre. In general, relatively healthy community dwelling elderly are more likely to participate in a study such as the Rotterdam Study (Herzog \& Rodgers, 1988; Kelsey et al., 1989). Application of exclusion criteria for dietary assessment analysis such as exclusion of nursing home residents and persons with a known reduced cognitive function may have further contributed to the formation of a relatively healthy cohort. Thus, we cannot exclude the possibility of an overrepresentation of persons with a dietary pattern similar to a healthier population, specifically, in the older age groups. If this is true, the observed decreased intake of most nutrients with age, especially in men, is probably underestimated as compared with the general population of this age.

Efficiency in dietary assessment was via two consecutive steps (Table 1). A checklist of foods completed by the participants at home made the subjects aware of their food consumption and the items marked by the participants informed the dietitian about the meal pattern and the foods consumed regularly. This, subsequently, allowed the dietitian to focus during the interview only on specification of amounts and frequencies of reported items during the interview. Thus, 
Table 5. Mean (SD) daily intake of energy and selected nutrients, energy distribution and nutrient density for selected nutrients of women in the Rotterdam Study

\begin{tabular}{|c|c|c|c|c|c|}
\hline & $\begin{array}{c}55-64 \text { years } \\
n=1331\end{array}$ & $\begin{array}{c}65-74 \text { years } \\
n=1193\end{array}$ & $\begin{array}{c}75-84 \text { years } \\
n=612\end{array}$ & $\begin{array}{c}85-95 \text { years } \\
n=73\end{array}$ & $\begin{array}{l}\text { Test for } \\
\text { trend } t\end{array}$ \\
\hline \multicolumn{6}{|l|}{ Nutrients } \\
\hline Energy (MJ) & $7.5(1.7)$ & $7.4(1.6)$ & $7.4(1.7)$ & $7.9(2.2)$ & $\mathrm{ns}$ \\
\hline \multicolumn{6}{|l|}{ Protein } \\
\hline total (g) & $78.6(16.8)$ & $75.1(16.3)$ & $74.1(17.4)$ & $75.1(22.4)$ & $* * *$ \\
\hline vegetable protein (g) & $26.7(7.2)$ & $25.7(7.0)$ & $24.4(6.5)$ & $25.2(7.1)$ & $* * *$ \\
\hline \multicolumn{6}{|l|}{ Fat } \\
\hline total (g) & $72.1(23.4)$ & $72.3(22.8)$ & $74.0(23.2)$ & $82.1(29.3)$ & * \\
\hline saturated fat (g) & $28.3(10.3)$ & $29.0(10.2)$ & $30.5(10.6)$ & $33.5(13.2)$ & $* * *$ \\
\hline mononunsaturated fat (g) & $24.6(8.5)$ & $24.3(8.6)$ & $24.8(8.6)$ & $27.6(11.1)$ & ns \\
\hline polyunsaturated fat (g) & $13.6(6.7)$ & $13.4(6.7)$ & $13.0(7.0)$ & $14.7(7.3)$ & * \\
\hline linoleic acid (g) & $11.4(6.5)$ & $11.1(6.4)$ & $10.6(6.6)$ & $11.6(6.7)$ & $* *$ \\
\hline \multicolumn{6}{|l|}{ Carbohydrates } \\
\hline total $(\mathrm{g})$ & $195.4(53.9)$ & $195.5(49.6)$ & $195.9(52.3)$ & $207.8(68.5)$ & ns \\
\hline mono/disaccharides (g) & $97.8(36.6)$ & $99.7(35.0)$ & $103.5(38.6)$ & $111.5(47.4)$ & $* * *$ \\
\hline polysaccharides (g) & $96.9(26.9)$ & $95.2(24.5)$ & $91.5(23.8)$ & $94.7(29.6)$ & $* * *$ \\
\hline Cholesterol (mg) & $217(70)$ & $214(71)$ & $219(74.5)$ & $243(93)$ & ns \\
\hline Dietary fibre (g) & $16.5(4.8)$ & $15.8(4.5)$ & $15.3(5.0)$ & $16.0(8.8)$ & $* * *$ \\
\hline Water $(\mathrm{ml})$ & $2483(614)$ & $2391(596)$ & $2334(554)$ & $2216(632)$ & $* * *$ \\
\hline Alcohol (g)‡ & $9.4(11.7)$ & $8.4(10.9)$ & $5.8(8.3)$ & $5.4(8.8)$ & $* * *$ \\
\hline \multicolumn{6}{|l|}{ Energy density } \\
\hline Cholesterol (mg MJ $\left.{ }^{-1}\right)$ & $29.1(7.6)$ & $29.0(7.7)$ & $29.6(7.6)$ & $30.6(7.0)$ & ns \\
\hline Dietary fibre $\left(\mathrm{g} \mathrm{MJ}^{-1}\right.$ ) & $2.3(0.6)$ & $2.2(0.6)$ & $2.1(0.7)$ & $2.0(0.7)$ & $* * *$ \\
\hline \multicolumn{6}{|l|}{ Energy distribution } \\
\hline \multicolumn{6}{|l|}{ Energy from: } \\
\hline protein \% & $17.8(3.2)$ & $17.2(3.0)$ & $17.0(3.1)$ & $16.2(3.2)$ & $* * *$ \\
\hline fat $\%$ & $35.7(6.3)$ & $36.2(6.19)$ & $37.2(6.4)$ & $38.6(6.3)$ & $* * *$ \\
\hline saturated fat \% & $14.0(3.2)$ & $14.5(3.3)$ & $15.4(3.6)$ & $15.7(3.2)$ & $* * *$ \\
\hline carbohydrates \% & $43.6(6.9)$ & $44.2(6.6)$ & $44.2(6.7)$ & $43.8(5.8)$ & * \\
\hline mono/disaccharides \% & $21.7(6.2)$ & $22.4(5.8)$ & $23.3(6.3)$ & $23.3(5.3)$ & $* * *$ \\
\hline
\end{tabular}

†Test for trend across age groups (55-64 years, 65-74 years, 74-95 years).

ns $=$ not significant.

$* P<0.05$.

$* * P<0.001$.

$* * * P<0.0001$.

$\ddagger$ Mean alcohol consumption of women drinking alcohol (73\%).

respondent burden, which is seen as a specific problem of dietary assessment in the elderly (Kelsey et al., 1989; van Staveren et al., 1994), was kept low. Time for completion of the selfadministered questionnaire averaged $20 \mathrm{~min}$ and another $20 \mathrm{~min}$ were allocated for the dietary interview. Thus, total time for dietary assessment was approximately $40 \mathrm{~min}$. Combination of methods, use of memory strategies or prior notification of a dietary interview have been shown previously to be useful in obtaining accurate and complete recalls in elderly people (Chiannetta \& Head, 1992). A visual check of formal completeness of the self-administered questionnaire and by the dietitians, their professional judgement concerning unreliable dietary assessment (3.8\% unreliable dietary assessments) and logical checks built into the interactive data entry program further ensured that complete recalls were obtained.

The presence of over- and underreporting 
Table 6. Mean (SD) daily intake of selected vitamins and minerals of women in the Rotterdam Study

\begin{tabular}{lccccc}
\hline & $\begin{array}{c}55-64 \text { years } \\
n=1331\end{array}$ & $\begin{array}{c}65-74 \text { years } \\
n=1193\end{array}$ & $\begin{array}{c}75-84 \text { years } \\
n=612\end{array}$ & $\begin{array}{c}85-95 \text { years } \\
n=73\end{array}$ & $\begin{array}{c}\text { Test for } \\
\text { trendt }\end{array}$ \\
\hline Minerals & & & & & \\
$\quad$ Calcium (mg) & $1125(386)$ & $1090(349)$ & $1115(381)$ & $1134(551$ & $\mathrm{ns}$ \\
Phosphor (mg) & $1697(754)$ & $1612(727)$ & $1610(724)$ & $1619(820)$ & $* * *$ \\
Iron (m) & $11.5(2.5)$ & $11.0(2.4)$ & $10.4(2.5)$ & $10.8(3.5)$ & $* * *$ \\
Sodium (m)§ & $2092(582)$ & $1993(532)$ & $1964(564)$ & $2061(699)$ & $* * *$ \\
Potassium (mg) & $3590(765)$ & $3469(729)$ & $3381(798)$ & $3450(998)$ & $* * *$ \\
Magnesium (mg) & $298(66)$ & $285(62)$ & $277(65)$ & $285(80)$ & $* * *$ \\
Zinc (m) & $10.2(2.3)$ & $9.7(2.3)$ & $9.6(2.5)$ & $9.6(2.9)$ & $* * *$ \\
Vitamins & & & & & \\
Vitamin A (mg RE) & $0.76(0.37)$ & $0.76(0.37)$ & $0.77(0.34)$ & $0.89(0.47)$ & $\mathrm{ns}$ \\
$\beta$-carotene (mg) & $1.61(0.79)$ & $1.46(0.79)$ & $1.41(0.94)$ & $1.37(0.53)$ & $* * *$ \\
Thiamin (mg) & $1.07(0.26)$ & $1.02(0.25)$ & $0.99(0.27)$ & $1.00(0.28)$ & $* * *$ \\
Riboflavin (mg) & $1.51(0.48)$ & $1.47(0.46)$ & $1.50(0.50)$ & $1.60(0.74)$ & $\mathrm{ns}$ \\
Pyridoxine (mg) & $1.50(0.34)$ & $1.46(0.32)$ & $1.42(0.34)$ & $1.40(0.38)$ & $* * *$ \\
Niacin (m) & $9.7(2.7)$ & $8.9(2.7)$ & $8.1(2.4)$ & $8.0(2.6)$ & $* * *$ \\
Tocopherol (mg eqv) & $12.8(5.5)$ & $12.8(5.5)$ & $12.5(5.7)$ & $13.9(5.9)$ & $\mathrm{ns}$ \\
Vitamin C (g) & $125.8(55.0)$ & $123.5(2.7)$ & $123.3(64.2)$ & $121.6(47.7)$ & $\mathrm{ns}$ \\
\hline
\end{tabular}

†Test for trend across age groups (55-64 years, 65-74 years, 74-95 years). ns $=$ not significant.

$* P<0.05$.

$* * P<0.001$.

$* * * P<0.0001$.

$\S$ Sodium intake from food only.

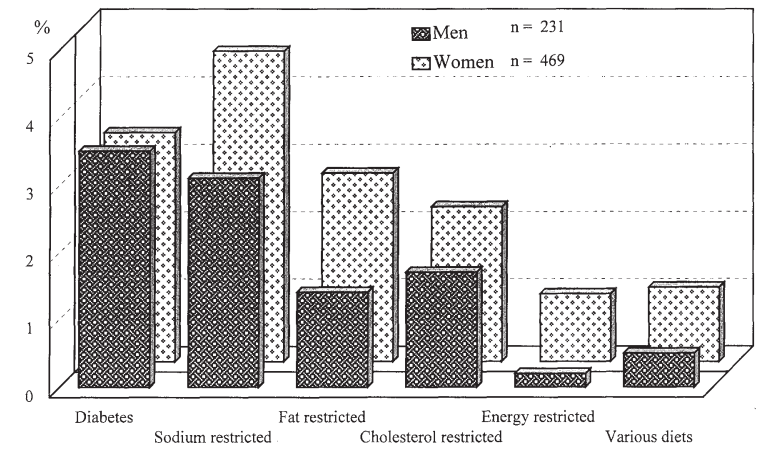

Fig. 1. Men and women following different types of prescribed diet in the Rotterdam Study.

in dietary assessment has been extensively documented for various methods and for diverse populations and age groups (Black et al., 1991). Studies using the doubly labelled water method to assess total energy expenditure confirmed that self-reports of energy and food intake tend to be underestimated (Livingstone et al., 1990; Goran \& Poehlman, 1992; Black et al., 1993). Underestimation of food intake may be due to the tendency of subjects to conceal their true dietary intake consciously or unconsciously. Some authors suggested underreporting to be dependent on the degree of obesity (De Vries 
et al., 1994; Lichtman et al., 1992) and for elderly women adiposity was shown to be an independent predictor of underreporting (Johnson et al., 1994). In our study population of 5434 elderly subjects the ratio of energy intake to basal metabolic rate (EI/BMR) was significantly associated with age (Table 2), which can be partially explained by the observed significant decrease of estimated BMR with age. EI/BMR was also found to be significantly inversely associated with BMI (Pearsons $r=0.36, P>0.0001)$. Stratification by age $(<65,65-74,>74$ years $)$ revealed that EI/BMR significantly decreased across categories of $\mathrm{BMI}(<25,25-30,>30)$ suggesting underreporting of obese subjects independent of age.

The results of this study are generally in accordance with other surveys of smaller size conducted in this age group in the Netherlands, despite the use of a different FFQ or a different methodology for dietary assessment (Löwik et al., 1990, 1994; Moreiras-Varela et al., 1991; Grootenhuis et al., 1995). However, some differences were observed. Intakes of protein and vitamin C were consistently lower, whereas intakes of fat, saturated fat, cholesterol and dietary fibre were consistently higher in the present study. Differences may be partly attributable to the use of an updated food composition table in the present study. Changes in the composition of foods and improvements in the quality of data in the current food composition table were shown to be the major cause of changes in dietary fibre and fat intake estimates in the Dutch National Food Consumption Survey in 1987/88 compared with 1992 (Hulshof et al., 1995).

Comparison with large-scale studies in the elderly conducted in the US revealed some differences (Block \& Subar, 1992; Munger et al., 1992; Mares-Perlman et al., 1993). Nutrient estimates derived in the Rotterdam Study showed good agreement on macronutrient level with nutrient estimates obtained by the FFQ method in the Iowas Women Study (Munger et al., 1992). For calcium, however, the Dutch estimates were considerably higher ( $300 \mathrm{mg} \mathrm{day}{ }^{-1}$ ), whereas for vitamin A (retinol and b-carotene), vitamin $\mathrm{C}$ and the $\mathrm{B}$ vitamins the estimates were lower. In the Beaver Dam Study (Mares-Perlman et al., 1993) nutrient estimates obtained by diet history questionnaire (age group 65-84 years) were considerably lower compared with the Rotterdam Study except for vitamin B complex and vitamin C. Similar results were found for the Ross Laboratories Elderly Dietary Survey (RLEDS) (Ryan et al. 1992), in which diet was assessed by 24-h recall and in the 1987 National Health Interview Survey (NHIS) (Block \& Subar, 1992) using a 60-item FFQ. In summary, dietary intake of most nutrients in the elderly of the Rotterdam Study compared with the US studies cited has been found to be generally higher, except for vitamin $\mathrm{C}$ and B vitamins (thiamin, riboflavin, pyridoxine, niacin). The widespread use of products fortified with vitamin B complex and other vitamins/minerals in the USA may explain this observation.

A substantial proportion of the subjects in our study followed a prescribed dietary regimen, as in other studies in the elderly (Löwik et al., 1994). Prescribed diets were more prevalent among women than among men. The number of persons reporting a prescribed diet increased significantly with age (Table 2). Because we assume that prescribed diets are consumed over a relatively long period and because we are interested in average dietary intake over a longer period (preceeding year) we did not exclude subjects following a prescribed diet from the analysis.

Dietary supplements, especially vitamin and mineral preparations, are generally regarded as important sources of micronutrients. Supplement use in the Rotterdam Study was not recorded with sufficient accuracy to incorporate vitamin and mineral intake through supplements in the computation of nutrient intakes. However, data on supplement use as collected in our study provide enough precision to classify individuals correctly as users or nonusers in the past year of those supplements (Dorant et al., 1994). In a validation study using the same method, a sensitivity of $65.9 \%$ and a specificity of $98.5 \%$ were reported with a kappa statistic of 0.69 (Dorant et al., 1994) for classification of users or nonusers of the past year. The use of supplements and vitamin/mineral supplements in the Rotterdam Study was higher than reported in the Dutch National Food Consumption survey (Dorant et al., 1993; Löwik et al., 1994) and the National Diet and 
Nutrition Survey in the elderly in the UK (Bates et al., 1998), but considerably lower than that observed in American elderly, where figures range from $28 \%$ in the NHIS (Block \& Subar, 1992) to $60 \%$ in the Iowas Women Study (Munger et al., 1992).

In summary, we have described a new twostep dietary assessment approach for use in epidemiological studies in the elderly, applied it across a wide age range in a large elderly population and reported estimates of nutrient intake. We conclude that the adapted SFFQ facilitated collection of data on dietary habits in the elderly within a limited time frame and consider it to be a suitable instrument for dietary assessment in largescale epidemiological studies.

\section{Acknowledgments}

We thank the participants of the Rotterdam Study, the research dietitians, field workers and computer assistants for their enthusiasm and skilfull contributions to the data collection. This study has been supported by grants from the NESTOR programme for research in the elderly (supported by the Netherlands Ministries of Health and Education), the Rotterdam Medical Research Foundation (ROMERES). K.K.-G. was supported by grants from the Netherlands Institute of Health Sciences, and the Federal State of Brandenburg, Germany.

\section{References}

Bates, C.J., Prentice, A., van der Pols, J.C., Walmsley, C., Pentieva, K.D., Finch, S., Smithers, G. \& Clarke, P.C. (1998) Estimation of the use of dietary supplements in the National Diet and Nutrition Survey: People aged 65 years and over. An ovserved paradox and a recommendation. Eur. J. Clin. Nutr. 52, 917-923.

Beaton, G.H., Milner, J., Corey, P., McGuire, V., Cousins, M., Stewart, E., de Ramos, M., Hewitt, D., Grambsch, P.V. \& Little, J.A. (1983) Source of variance in 24-hour dietary recall data: implications for nutrition study design and interpretation. Am. J. Clin. Nutr. 32, 2546-2559. Black, A.E., Goldberg, G.R., Jebb, S.A., Livingstone, M.B.E., Cole, T.J. \& Prentice, A.M.
(1991) Critical evaluation of energy intake data using principles of energy physiology: 2 . Evaluating the results of published surveys. Eur. J. Clin. Nutr. 45, 583-599.

Black, A.E., Prentice, A.M., Goldberg, G.R., Jebb, S.A., Bingham, S.A., Livingstone, M.B.E. \& Coward, W.A. (1993) Measurements of total energy expenditure provide insight into the validity of dietary measurements of energy intake. J. Am. Diet. Assoc. 93, 572-579.

Block, G. \& Subar, A.F. (1992) Estimates of nutrient intake from a food frequency questionnaire: The 1987 National Health Interview Survey. J. Am. Diet. Assoc. 92, 969-977.

Chiannetta, M.M. \& Head, M.K. (1992) Effect of prior notification on accuracy of dietary recall in the elderly. J. Am. Diet. Assoc. 92, 741-743.

De Vries, J.H., Zock, P.L., Mensink, R.P. \& Katan, M.B. (1994) Underestimation of energy intake by 3-d records compared with energy intake to maintain body weight in 269 nonobese adults. Am. J. Clin. Nutr. 60, 855-860.

Department of Health. (1994) Dietary reference values for food energy and nutrient for the United Kingdom. Annex 2. London: HMSO.

Dorant, E., van den Brandt, P.A., Goldbohm, R.A., Hermus, R.J.J. \& Sturmans, F. (1994) Agreement between interview data and a self-administered questionnaire on dietary supplement use. Eur. J. Clin. Nutr. 48, 180-188.

Dorant, E., van den Brandt, P.A., Hamstra, A.M., Feenstra, M.H., Goldbohm, R.A., Hermus, R.J.J. \& Sturmans, F. (1993) The use of vitamins, minerals and other dietary supplements in the Netherlands. Internat. J. Vit. Nutr. Research 63, 4-10.

Food and Nutrition Council. (1993) Dutch food composition table (NEVO). The Hague, Netherlands: Voorlichtingsbureau voor de Voeding (in Dutch).

Garrow, J.S. (1995) Validation of methods for estimating habiutal diet: proposed guidelines. Europ. J. Clin. Nutr. 49, 231-232.

Goldbohm, R.A., van den Brandt, P.A., Brants, H.A.M., vant Veer, P., Sturmans, F. \& Hermus, R.J.J. (1994) Validation of a dietary questionnaire used in a large-scale prospective cohort study on diet and cancer. Eur. J. Clin. Nutr. 48, 253-265.

Goldbohm, R.A., vant Veer, P., van den Brandt, P.A., vant Hof, M.A., Brants, H.A.M., Sturmans, F. \& Hermus, R.J.J. (1995) Reproducibility of a food frequency questionnaire and stability of dietary habits determined from five annually repeated measurements. Eur. J. Clin. Nutr. 49, $420-429$.

Goran, M.I. \& Poehlman, E.T. (1992) Total Energy 
expenditure and energy requirements in healthy elderly persons. Metabolism 41, 744-753.

Grootenhuis, P.A., Westerbrink, S., Sie, C.M., de Neeling, J.N., Kok, F.J. \& Bouter, L.M. (1995) A semiquantitative food frequency questionnaire for use in epidemiologic research among the elderly: validation by comparison with dietary history. J. Clin. Epidemiol. 48, 859-868.

Herzog, A.R. \& Rodgers, W.L. (1988) Age and response rates to interview sample surveys. $J$. Gerontol. 43, S2000-S2005.

Hofman, A., Grobbee, D.E., De Jong, P.T.V.M. \& Vandenouweland, F.A. (1991) Determinants of disease and disability in the elderly: The Rotterdam Elderly Study. Eur. J. Epidemiol. 7, 403-422.

Hulshof, K.F.A.M., Löwik, M.R.H. \& Kistemaker, L. (1995) Changes in the composition of the Dutch diet. Abstract; Second International Conference on Dietary Assessment Methods. Boston.

Johnson, R.K., Goran, M.I. \& Poehlman, E.T. (1994) Correlates of over-and underreporting of energy intake in healthy older men and women. Am. J. Clin. Nutr. 59, 1286-1290.

Kelsey, J.L., OBrien, L.A., Grisso, J.A. \& Hoffman, S. (1989) Issues in carrying out epidemiologic research in the elderly. Am. J. Epidemiol. 130, 857-867.

Klipstein-Grobusch, K., den Breeijen, J.H., Goldbohm, R.A., Geleijnse, J.M., Hofman, A., Grobbee, D.E. \& Witteman, J.C.M. (1998) Dietary assessment in the elderly: validation of a semiquantitative food frequency questionnaire. Eur. J. Clin. Nutr 52, 588-596.

Lichtman, S.W., Pisarska, K., Berman, E.R., Pestione, M., Dowling, H., Offenbacher, E., Weisel, H., Heshka, S., Matthews, D.E. \& Heymsfiled, S.B. (1992) Discrepancy between self-reported and actual caloric intake and excercise in obese subjects. N. Engl. J. Med. 327, 1893-1898.

Livingstone, M.B.E., Prentice, A.M., Strain, J.J., Coward, W.A., Black, A.E., Barker, M.E.,
Mckenna, P.G. \& Whitehead, R.G. (1990) Accuracy of weighed dietary records in studies of diet and health. Br. Med. J. 300, 708-712.

Löwik, M.R.H., Brussaard, J.H., Hulshof, K.F.A.M., Kistemaker, G.S., Ockhuizen, T. \& Hermus, R.J.J. (1994) Adequacy of the diet in the Netherlands in 1987-88 (Dutch Nutrition Surveillance System). Int. J. Food Sci. Nutr. 45, S1-S62.

Löwik, M.R.H., Westenbrink, S., Hulshof, K.F.A.M., Kistemaker, C. \& Hermus, R.J.J. (1990) Nutrition and aging: Dietary intake of apparently healthy elderly - The Dutch Nutrition Surveillance System. J. Am. Coll. Nutr. 8, 347-356.

Mares-Perlman, J.A., Klein, B.E.K., Klein, R., Ritter, L.L., Freudenheim, J.L. \& Luby, M.H. (1993) Nutrient supplements contribute to the dietary intake of middle- and older-aged adult residents of Beaver Dam, Wisconsin. J. Nutr. 123, 176-188.

Moreiras-Varela, O., van Staveren, W.A., Amorim Cruz, J.A., Nes, M. \& Lund-Larssen (1991) Intake of energy and nutrients. Euronut SENECA Investigators. Eur. J. Clin. Nutr. 45, S105-S120.

Munger, R.G., Folsom, A.R., Kushi, L.H., Kaye, S.A. \& Sellers, T. (1992) Dietary assessment of older Iowa women with a food frequency questionnaire: Nutrient intake, reproducibility, and comparison with 24-hour dietary recall interviews. Am. J. Epidemiol. 136, 192-200.

Ryan, A.S., Craig, L.D. \& Finn, S.C. (1992) Nutrient intakes and dietary patterns of older Americans: a national study. J. Gerontol. 47, M145-M150.

Van den Brandt, P.A., Goldbohm, R.A., vant Veer, P., Volovics, A., Hermus, R.J.J. \& Sturmans, F. (1990) A large-scale prospective cohort study on diet and cancer in the Netherlands. J. Clin. Epidemiol. 121, 783-790.

Van Staveren, W.A., de Groot LCPGM, Blauw, Y.H. \& van der Wiele, R.P.J. (1994) Assessing diets of elderly people: problems and approaches. Am. J. Clin. Nutr. 59, 221S-23.

Willett, W.C. \& Stampfer, M.J. (1986) Total energy intake: implications for epidemiologic analysis. Am. J. Epidemiol. 124, 17-27.

Submitted October 1998, Revised January 1999, Accepted April 1999 